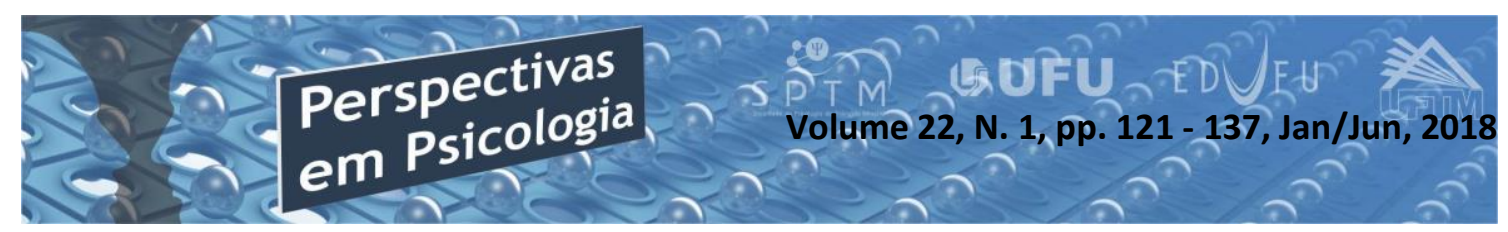

\title{
PSICANÁLISE E CONTOS DE FADAS NO PROCESSO DE ELABORAÇÃO DO LUTO INFANTIL
}

\author{
Jennifer Guimarães de Moura \\ Maria de Fátima Pessoa Assis \\ (Universidade Federal de Goiás - Regional Jataî))
}

\begin{abstract}
Resumo
O presente trabalho pretende realizar uma reflexão sobre o processo de elaboração do luto infantil e investigar como os contos de fadas podem ser utilizados como amparo ao funcionamento psíquico infantil, auxiliando a solucionar as demandas vividas pelas crianças que passam pelo processo de luto. O presente estudo foi construído por meio de pesquisa teórica e bibliográfica em artigos, livros e em bases indexadas referentes principalmente ao período 2010/2016, sob a ótica da abordagem psicanalítica.
\end{abstract}

Palavras-chave: Luto; Psicanálise; Infância; Histórias Infantis; Narratividade.

\section{Abstract \\ Psychoanalysis and Fairy Tales in the Process of Elaboration of Children's Mourning}

The present work intends to carry out a reflection on the elaboration process of the children's mourning and to investigate how the fairy tales can be used as a support to the psychic operation of the child, helping to solve the demands life by the children who go through the process of mourning. The present study was constructed through theoretical and bibliograpjic research in articles, books and indexed databases referring mainly to the period 2010/2016, from the perspective of the psychoanalytic approach.

Key Words: Mourning; Psychoanalysis; Childhood; Children's Stories; Narrativity.

\section{Introdução}

Este trabalho partiu do interesse pela questão de como se dá o processo de elaboração do luto infantil e como os familiares e outros integrantes do meio social da criança lidam com situações onde a morte se faz presente. Parte-se do pressuposto de que a necessidade de conversar com a criança sobre a perda se torna extremamente relevante, pois a maneira como se anuncia a morte pode auxilia-la a dar início ao seu processo de 
elaboração do luto que está relacionado a necessidade de reestruturação do ego ${ }^{1}$.

Parte-se também do pressuposto de que, sendo toda a linguagem metafórica, por configurar-se como uma substituição daquilo que falta ao sujeito, o uso de metáforas e de maneiras sutis para conversar sobre a morte são recursos que auxiliam os adultos a tratar das perdas de maneira menos dolorosa para eles e para quem ouve. Com efeito, as metáforas são ferramentas que possibilitam a compreensão do que é a morte de maneira menos penosa, pois oferece meios para a criança fantasiar sobre a perda, criando soluções alternativas que funcionam como mecanismo de reinvestimento libidinal. (Gutfreind, 2003)

O diálogo entre o adulto e a criança tem se tornado cada vez mais raro, nos tempos de hoje, quando quase nunca há tempo suficiente para cumprir com todas as tarefas que nos comprometemos. Neste contexto, os pais e filhos se distanciam, tradições culturais e familiares se perdem,

\section{Luto e luto infantil: histórico e}

\section{definições}

Quando a questão do luto é abordada, inicialmente nos traz a ideia da perda pela morte física de um ser amado, entretanto, o sentimento do luto abrange entre elas, o hábito de contar histórias as crianças.

$\mathrm{O}$ ato de contar histórias aos filhos e netos proporciona a ambos maior estreitamentos dos laços afetivos, cria um espaço único onde tudo pode ser compartilhado, onde se torna possível, na fantasia da criança (ao ouvir histórias de superação de heróis que se parecem com eles, personagens que tem seus sofrimentos, perdas e obstáculos) o que causa nela um impacto positivo, pois o herói que é o seu ídolo consegue superar todas as dificuldades impostas.

$\mathrm{O}$ enfrentamento da realidade que tem a morte como protagonista é doloroso a todos, pois causa ao ego a sensação de morte de si mesmo, além disso, o processo de elaboração da perda é uma experiência singular. Sendo assim, a cada um cabe seu próprio tempo para que seja realizado o desinvestimento libidinal do objeto de amor perdido e o reinvestimento dessa energia psíquica no próprio ego e em outro objeto substituto. (Freud, 1917/1974).

perdas que vão além do aspecto vivo e físico. O processo de luto está presente em todo o desenvolvimento do ser humano, desde a mais tenra infância à senilidade. 
Freud em sua obra Luto $e$ Melancolia (1917/1974) salienta que o luto é o sentimento de perda de um ente querido, perda de um objeto de amor que teve seu investimento libidinal e posteriormente tornou-se inacessível. O objeto de amor abrange todo e qualquer objeto seja este real ou simbólico, material ou ideal. O ideia de perda é interpretada de forma mais abrangente, não se resumindo a perda pela morte, mas englobando todas as maneiras de afastamento, impossibilidades de encontro entre o sujeito e seu objeto. Desse modo, podemos compreender que o processo de luto na visão psicanalítica freudiana não se resume apenas a morte, mas a qualquer forma de perda e sendo assim, o ser amado real ou ideal pode não ter morrido, mas apenas ter sido perdido enquanto objeto de amor e investimento libidinal, o que resulta em sofrimento.

O luto é um processo doloroso para o ego que teve seu objeto de amor perdido e que para dar conta da nova realidade, deverá deslocar seu investimento para novos objetos, entretanto, esse processo de elaboração demanda tempo para se estruturar de maneira saudável. (Freud,1917/1974).

A elaboração do processo de luto não ocorre de maneira linear, uma vez que os sentimentos característicos deste não surgem no momento exato, quando se toma conhecimento da perda, e também não desaparecem sozinhos com o passar do tempo. Sendo assim, trata-se de idas e vindas em que se dá a experiência de perda e recuperação do objeto de amor que se foi, ou simbolização do luto.

Cabe ao ego realizar um complexo trabalho de adaptação à nova realidade, o enfrentamento das angústias, ansiedades e tristezas, todos aqueles sentimentos, emoções e pensamentos que causam demasiado desconforto ao ego. Entretanto, além de encarar essa nova realidade e lidar com todo o sofrimento que ela traz, o sujeito busca se organizar com o objetivo de se reestruturar e aprender a lidar com a nova realidade que o cerca. (Freud, 1917/1974).

Desde a contribuição de Freud para a interpretação do que acontece com o ego quando se vê em processo de elaboração do luto, não há conceptualizações que tornem o luto uma doença a ser medicada, o que pode produzir o luto como processo patológico o que envolve mais variáveis, como apontado por Freud em Luto e Melancolia (1917/1974).

De acordo com Freud (1917/1974) a melancolia se assemelha ao luto em alguns do seus sintomas, e também aproxima-se do processo de regressão, como a escolha objetal narcísica. A melancolia é uma reação do ego perante a perda real de um objeto amado, durante esse período há possibilidade da ocorrência da ambivalência nas relações amorosas, que 
propicia o quadro de neurose obsessiva. A ambivalência se torna manifesta e efetiva quando é expressa através da autorecriminação, ou seja, a pessoa que está vivendo o processo de luto se vê como culpada pela morte do objeto amado, pois desejou sua morte em algum momento.

Como podemos verificar no texto freudiano, o luto patológico é visto como melancolia, que possui aspectos semelhantes ao processo de elaboração do luto, entretanto, há diferenças singulares que tornam a melancolia um processo ainda mais devastador e contínuo, por corolário, torna a elaboração e reestruturação do ego mais complexa.

No luto normal, há o desinvestimento no meio externo, contexto em que o mundo se torna empobrecido e vazio, e somente com o tempo, o ego se torna novamente abastecido de libido para reinvesti-la nos objetos. Na melancolia o próprio ego é desinvestido e desacreditado, quando há o abandono deste e a introdução de sistemas de autoacusação e recriminação. (Freud, 1917/1974).

Ainda sobre a visão psicanalítica sobre o luto, há contribuições relevantes que Melanie Klein elaborou sobre o que acontece com o psiquismo do sujeito ao vivenciar o enfrentamento do luto. A priori, vale pontuar que para Klein (1940/1996) a perda que oriunda o processo de luto engloba objetos reais e também simbólicos, cenário em que o sofrimento pode ser advindo tanto da morte de uma pessoa amada, como também da perda de um objeto que tenha valor sentimental e não necessariamente valioso no aspecto financeiro.

Para Klein, o luto traz à tona os sentimentos depressivos arcaicos, que são todos os lutos presentes no processo de desenvolvimento e crescimento do sujeito, desde as perdas simbólicas do seio bom e a prevalência do seio mal persecutório, sendo assim, considera-se o luto como um processo primitivo, como é possível identificar em sua obra $O$ luto $e$ suas relações com os estados maníacos depressivos:

No meu ponto de vista, a dor trazida pela perda da pessoa amada é muito ampliada pelas fantasias inconscientes do sujeito, que acredita ter perdido seus objetos internos "bons" também. Ele tem a impressão, portanto, de que os objetos internos "maus" tornaramse dominantes e que seu mundo interno corre o risco de se desintegrar. Sabemos que a perda da pessoa amada cria o impulso de reinstalar o objeto amado perdido dentro do ego (Freude Abraham). A meu ver, porém, o indivíduo não só joga para dentro de si (reincorpora) a pessoa que acaba de perder, como também reinstala os 
objetos bons internalizados (em última análise, os pais amados), que se tornaram parte de seu mundo interno desde as etapas mais arcaicas de seu desenvolvimento. Tem-se a impressão de que estes também foram destruídos sempre que se passa pela morte de uma pessoa querida. (Klein, 1996, p. 396).

Como podemos verificar, na ótica kleiniada (1940/1996) o indivíduo de fato está em agudo sofrimento quando encontrase em processo de luto, mas este último é um estado mental constitutivo do enfrentamento da perda do objeto e, sendo assim, o luto não é considerado doença.

A diferenciação feita por Melanie Klein entre o processo de luto normal, e o luto considerado anormal, que pode ser observado em quadros maníacos depressivos, é assim designada:

A diferença fundamental entre $o$ luto/1996 normal, de um lado, e o luto anormal $\boldsymbol{e}$ os estados maníacodepressivos, de outro, é a seguinte: o maníaco-depressivo é a pessoa que fracassa no trabalho do luto, apesar de poderem apresentar defesas completamente diferentes, têm em comum o fato de não terem conseguido estabelecer seus objetos "bons" internos no início da infância e de não se sentirem seguros no seu mundo interior. (Klein, 1996, p. 412).

$\mathrm{Na}$ descrição do processo de elaboração da noção de luto, tal qual abordado por Freud (1917/1974) e Klein (1940/1996) observa-se mais semelhanças do que divergências. Cada autor traz a sua teoria de acordo com seus próprios estudos, mas ao final concordam que nesse processo o ego deve retornar ao estado em que se encontrava antes da perda, seja através do desinvestimento libidinal no objeto de amor perdido (o que torna o ego desinibido e favorável a novos investimentos em objetos internos e externos) como defende Freud (1917/1974), seja pelo retornar ao estado em que estava, antes do luto, através da estabilidade de um mundo interno harmonioso e rico em objetos bons, como salienta Klein (1940/1996).

O Manual de Diagnóstico e Estatística de Transtornos Mentais DSM-V (2013) apresenta o luto juntamente com o diagnóstico de episódio depressivo maior, pois há sintomas semelhantes em ambos os diagnósticos, fator que acentua a relevância da análise clínica para a identificação e distinção entre os mesmos. A relação entre o luto e o episódio depressivo maior pode ser observada devido a possibilidade de ambos ocorrerem simultaneamente, ou seja, o luto não vivenciado de maneira normal é intensificado em seus sintomas, tornando- 
os contínuos. O luto, apesar de penoso, não costuma provocar o episódio depressivo maior, além disso, a depressão em pessoas enlutadas tende a ocorrer naquelas que são mais vulneráveis a transtornos depressivos. Quando isso acontece, há a intervenção medicamentosa para o tratamento do quadro depressivo.

Ainda de acordo com o DSM-V (2013), o transtorno depressivo maior pode ser diagnosticado a partir de apenas um único episódio, entretanto, estes se tornam frequentes na maioria dos casos, sendo que cada episódio de depressão maior pode ter a duração de até duas semanas, podendo variar para menos ou para mais. Os sintomas característicos e que também estão presentes no luto dito normal são: sentimento de tristeza, redução ou ausência de apetite, perda de peso, insônia entre outros.

Mesmo que ambos, episódios depressivo e luto, possam coincidir em alguns aspectos, o DSM-V descreve as discrepâncias entre os quadros:

Ao diferenciar luto de um episódio depressivo maior (EDM), é útil considerar que, no luto, o afeto predominante inclui sentimento de vazio e perda, enquanto no EDM há humor deprimido persistente $e$ incapacidade de antecipar felicidade ou prazer. A disforia no luto pode diminuir de intensidade ao longo de dias a semanas, ocorrendo em ondas, conhecidas como "dores do luto". Essas ondas tendem a estar associadas a pensamentos ou lembranças do falecido. $O$ humor deprimido de um EDM é mais persistente e não está ligado a pensamentos ou preocupações específicas. (Manual de Transtornos Mentais Diagnóstico e Estatístico DSM-V, 2013, p.126).

O transtorno de adaptação descrito no DSM-V (2013) constitui-se também de aspectos que englobam os sintomas caraterísticos do luto. Como descrito no manual, o transtorno de adaptação pode ser diagnosticado em casos onde há perda de um ente querido, em que o processo de elaboração da perda extrapola o tempo e se torna longo demais, tempo este que é definido pelo meio cultural onde o sujeito está inserido, relativo a sua cultura, religião e faixa etária.

Do mesmo modo como descrito no manual citado acima, o luto é mencionado na Classificação Internacional de Doenças CID 10 (1997) e associado ao transtorno de adaptação (F43.2). Ele é considerado como sintoma oriundo do estado de sofrimento emocional subjetivo, que ocorre em um período de adaptação devido a alguma mudança demasiadamente relevante e também provedora de stress. A intensidade 
do estresse vivenciado pelo sujeito afeta o ambiente social deste, o que faz eclodir as angústias e ansiedades caraterísticas do luto e das experiências de separação e perda.

Todos os processos que vivenciamos ao longo da vida são cercados de ritos de passagens, advindos do âmbito cultural e social. Ao finalizar uma fase da vida, para dar início a etapa seguinte, o sujeito perde aquilo que tinha para si, isto é, seus objetos de investimentos são perdidos e ele sofre por isso, o que acarreta o esvaziamento simbólico da sua vida anterior, o que o faz caminhar em busca de se reestruturar, parar lidar com a nova realidade. Todo esse processo é experimentado através das circunstâncias do meio cultural, o que pode resultar em sintomas que caracterizam o luto.

O processo de luto caracterizado como anormal por Klein (1940) e classificado como da ordem da melancolia por Freud (1915) é denominado como transtorno do luto complexo persistente no manual DSM-V (2013) e caracteriza-se por determinadas reações do sujeito ao sofrimento reativo a morte, coadunando-se em perturbação social e perturbação da identidade.

As características diagnósticas do transtorno do luto complexo persistente que o distingue do luto normal, são descritas com os seguintes critérios de análise e avaliação clínica:
O transtorno do luto complexo persistente é diagnosticado somente se ao menos 12 meses (seis meses em crianças) se passaram desde a morte de alguém com quem o enlutado tinha um relacionamento próximo (Critério A). Esse intervalo de tempo discrimina o luto normal do luto persistente. A condição envolve, em geral, uma saudade persistente do falecido (Critério Bl), que pode estar associada a intenso pesar e choros frequentes (Critério B2) ou preocupação com o falecido (Critério B3). (Manual de transtornos mentais DSM-V, 2013, p. 790).

A forma como o luto se manifesta em crianças é especificada e descrita no DSM-V, que aponta o processo doloroso de elaboração de luto expresso através das brincadeiras e no comportamento. Podem ocorrer regressões no desenvolvimento e comportamento ansioso ou de protesto em situações de separação e união. Em crianças menores predomina a angústia de separação e em crianças maiores a angústia social e de identidade, estas últimas são mais suscetíveis de produzirem a depressão.

Durante a infância a perda de um ente querido pode ser traumatizante dependendo das circunstâncias, casos onde ocorre a perda repentina dos pais ou daquele que cuida, situações que podem deixar a 
criança em choque, pois de repente se perde aquele que era a principal fonte de investimento amoroso de referências na estruturação de si mesmo.

Anton \& Favero (2011) em seu estudo sobre a morte repentina dos genitores e o luto infantil, apontam que do ponto de vista psicanalítico o trauma se trata de um choque violento capaz de romper a barreira protetora do ego, podendo acarretar perturbações duradouras sobre a organização psíquica do indivíduo. Tem como característica um período de desequilíbrio psicológico, resultante de um evento ou situação danosa, a qual o indivíduo não consegue resolver, pela utilização de seus mecanismos de defensas usuais, geralmente levando a um estado de crise.

A perda dos pais, ou do adulto que exerça a função paterna, quando ocorre de maneira abrupta, violenta ou prematura são mais complexas de serem elaboradas no psiquismo infantil. Como aponta Anton \& Favero (2011):

A maior crise com a qual uma criança pode se deparar é a morte repentina de um ou de ambos os pais, a qual afeta o sentimento de onipotência infantil, ao mostrar para a criança que seus pais não são seres superpoderosos, como imaginava. Da mesma forma, pode surgir culpa, por impulsos agressivos, que a criança acredita terem tornadose realidade, através da morte. Além disso, nas situações de morte repentina, diferentemente do que ocorre na morte esperada, a criança não tem a chance de fazer um luto antecipatório, de maneira a prepararse psicologicamente para tal evento. (Anton \& Favero, 2011, p. 102).

Crianças de cinco a sete anos veem a morte como algo reversível, como se fosse sono ou alguma separação, que em algum momento cessará e tudo voltara a ser como antes. Em casos assim é necessário que desmitifique a fantasia da criança, explicando de maneira clara e sensível o que é a morte, podendo fazer isso mediante exemplos, como a morte de algum animal de estimação, com isso, facilitando a compreensão da realidade. O esclarecimento dos fatos, apesar de doloroso é necessário, pois quando se engana a criança e esta descobre por si mesma a morte dos pais, a relação de confiança com os adultos é quebrada, o que resulta em sentimentos de raiva $\mathrm{e}$ frustração.

A partir dos oito anos, a morte é encarada como punição e cabe aos adultos esclarecer essa fantasia posteriormente, ou seja, com o amadurecimento do psiquismo e a maior compreensão da realidade, a morte passa a ser encarada como algo 
natural. Entretanto, independentemente da idade da criança, o fato ocorrido deve ser esclarecido de maneira compreensiva e sensível para não agravar ainda mais o sofrimento.

De acordo com a revisão bibliográfica realizada por Anton \& Favero (2011) são quatro fases que caracterizam o luto. A intensidade e duração de cada fase é sentida de modo singular. As quatros fases são:

A primeira fase - de torpor ou aturdimento - geralmente tem a duração de algumas horas ou semanas, podendo vir acompanhada de manifestações de desespero ou raiva. A segunda, denominada saudade e busca da figura perdida, pode durar meses ou anos, e caracteriza-se pelo impulso de buscar e recuperar o ente querido, sendo que a raiva pode mostrar-se presente, quando o indivíduo percebe realmente o fato a perda. Na terceira fase - desorganização e desespero - é frequente o choro, a raiva, acusações envolvendo pessoas próximas e uma

\section{O uso terapêutico do conto no Âmbito dos processos de luto}

Como instrumento para auxiliar no processo de elaboração do luto, especialmente quando se trata de crianças, há a possibilidade de utilizar os contos profunda tristeza, em virtude da constatação do caráter definitivo da perda. Nesta fase, podem surgir sentimentos mais depressivos, com sensação de que nada mais tem valor. Na quarta fase - organização - ocorre a aceitação da perda e a constatação de que uma nova vida precisa ser iniciada. Segundo o autor, a saudade, a necessidade do outro e a tristeza podem retornar em qualquer fase, já que o processo de luto nunca está totalmente concluído. (Anton \& Favero, 2011, p. 103).

Estudos realizados por Anton \& Favero (2011) mostram que em situações de perda repentina a fase dois é acentuada, pois há intensificação no protesto contra a morte e a busca pelo objeto de amor perdido. Aquele que vivencia o luto se empenha, na realidade ou em pensamento, para encontrar a figura perdida e durante esse processo há ambivalência de sentimentos onde se fazem presentes a raiva, a esperança e o desespero.

como recursos de comunicação entre terapeuta-paciente, de forma que esta seja facilitada. A vivencia emocional do luto quando não é elaborada pela criança, pode dificultar o trabalho psíquico de superação 
da perda do objeto de amor, e é neste contexto de auxílio ao processo de superação que o uso do conto pode ser de grande valia.

Quando ocorre a perda de um ente querido ou qualquer situação que envolve uma separação ou perda, os pais ou responsáveis presam por noticiar a criança de maneira suave, buscando não tornar a situação demasiadamente chocante. A dor e a tristeza são comuns em qualquer um que passe por situações de perda, no entanto, quando a morte é comunicada de maneira sensível e cuidadosa, colabora para a sua aceitação, o que faz com que seja possível a mobilização de recursos psíquicos de elaboração frente ao trauma da perda abrupta.

Zatti \& Kern (2014) afirmam que o contar histórias promove o amparo e o acolhimento, o que tornam as crianças capazes de se sentirem seguras e a vontade no setting criado para gerar conforto e resguardo. Quando a relação de confiança com o ambiente e com os participantes envolvidos é estabelecida, as crianças passam a utilizar os recursos da imaginação e da fantasia, que resultam no processo de simbolização de seus conflitos.

O contar histórias permite à criança se desenvolver gradativamente em direção a um movimento criativo, onde os conflitos conscientes e inconscientes serão externalizados e elaborados de forma a fornecer uma resolução, uma ressignificação que traga o alívio àqueles que sentem a angústia, mas não conseguem nomeá-la.

Oliveira (2006) ressalta que os contos de fadas permitem ao ser humano aprender a explorar o inconsciente e os horizontes que são fornecidos pelo imaginário. A autora defende que os contos possuem relevância na formação da personalidade humana, pois nestes há mecanismos que movimentam o raciocínio infantil e a vida de fantasia, dando subsídios para que quando adulto possam lidar com os obstáculos da vida real e assim conviver com as inseguranças e limitações presentes no mundo.

O estudo realizado por Carneiro \& Silva (2012) faz uma breve reflexão sobre os contos do escritor e poeta goiano Jose J. Veiga, os quais apresentam a temática "memória, morte e luto". É possível notar através do conto Invernada do sossego (onde crianças perdem o seu objeto de amor), que os personagens lidaram com a situação de perda de uma maneira particular. Os garotos fantasiavam que cavalgavam com seu estimado cavalo e tinham momentos felizes com ele.

A questão de brincar com o animal que não está mais presente materialmente, mas somente vivo na realidade psíquica das crianças, pode ser considerada algo surreal e patológico, mas inserido no âmbito da 
fantasia da criança, torna-se um meio de simbolizar e elaborar a perda.

Através deste conto de Veiga, percebemos que uma das formas que as crianças possuem para enfrentar o luto é criar um espaço onírico onde tudo é possível, onde não há regras e impedimentos para realizarem seus desejos. Utilizar contos que envolvem essa temática do luto no trabalho com crianças que passam por situações de perda auxilia na construção de um mecanismo lúdico que poderá ser usado por ela para lidar com a falta que sente. Com efeito, quando a criança não sabe o que fazer, busca a fantasia para confortar-se, pois no seu mundo psíquico há possibilidade de acalento e alivio para a dor da falta.

As crianças não se desfazem facilmente do elo que tinham com o morto, pois a memória é reativada constantemente. Isso não significa que não houve o entendimento do que é a morte, a separação irreversível e eterna, mas que apesar desta, houve anteriormente vivencias que estão guardadas na memória e que são ativadas por diferentes estímulos e são revividas pelas as crianças. Sendo assim, a morte não significa que o morto nunca existiu, mas que ele apenas não existe mais.

As experiências oriundas do luto são caracterizadas como fases do desenvolvimento humano comum aos ritos de passagem, nos quais todos os indivíduos vivenciarão em alguma etapa de suas vidas. De acordo Carneiro \& Silva (2012):

Para uma criança, receber a notícia da morte de um animal ou de um parente, de certa forma contribui para seu crescimento emocional e psíquico desde que a ocorrência seja noticiada com cuidados e com o devido apoio familiar. São os ritos de passagem, que em Antropologia apontam que precisamos passar por dificuldades para que, posteriormente, sintamos segurança e firmeza em relação à vida que levaremos: nessa "passagem para”, os meninos de J. J. Veiga estão $a$ crescer. $E$ todas as aventuras apontam sempre para esse rito de passagem, esse deslocamento da vida infantil e a entrada numa outra fase, menos infantil. (Carneiro \& Silva, 2012, p. 60-61).

A literatura é uma ferramenta muito relevante no desenrolar da infância, pois cada história que é contada para a criança leva consigo elementos de sua subjetividade, e auxiliam na elaboração e resolução de suas angústias, dúvidas e curiosidades.

Em nossa experiência com o projeto de extensão universitária "Ateliê de Contos" desenvolvido na instituição Casa da Criança - Amor e Arte, destinada a 
crianças de baixa renda, pudemos observar a riqueza do conto enquanto recurso mediador e facilitador da elaboração de processos de luto na criança. A título de ilustração, vamos nos remeter a um caso de uma criança que aqui nomearemos com o nome fictício de Igor, que havia perdido o pai há aproximadamente dois meses em acidente de motocicleta.

A metodologia desenvolvida no projeto consistiu de reuniões semanais com grupos de oito crianças, com a participação de alunos do curso de Psicologia, em que cabia a cada um papel específico a saber, um narrador, dois assistentes, um encarregado da dramatização com fantoches e um responsável pelas anotações da experiência.

Dentre as histórias selecionadas haviam contos clássicos e modernos, sendo que após a narrativa das histórias, acompanhadas da dramatização com uso de fantoches, as crianças tinham um espaço para recontar a sua maneira como haviam resignificado o conto em questão e em seguida também eram incentivadas a desenhar. Sendo assim, no momento designado para a roda de conversas, em um dos encontros em que a história Os Três Porquinhos foi narrada, Igor produziu um desenho em que colocava caminhos cruzados coloridos com tinta escura e carregada.
No encontro seguinte, em que a história Cabum foi contada ele trouxe todo o episódio do acidente do pai com detalhes. Desta maneira, Igor consegui elaborar a situação traumática, vivida recentemente, através da fala. Cabe ressaltar, que ambas as histórias escolhidas nos remetem a situações de perdas, ou seja, nos Três Porquinhos as casas frágeis são perdidas e os bichos precisam fugir em busca de abrigo; em Cabum encontramos o relato de um filhote de passarinho que ao tentar voar bate com a cabeça no chão e nunca mais consegue cantar.

Através da rica literatura, (composta de inúmeras formas como contos, metáforas, poesias e poemas, dentre tantas outras modalidades literárias), podemos obter auxílio nos momentos dos ritos de passagem, estes que envolvem mudanças, ou perdas que fazem parte do crescimento.

Neste contexto se faz presente famílias que em sua composição contam com as presença de avós e netos, onde há entre ambos convivência que possibilite as trocas simbólicas entres aqueles que são os "antepassados" e os "descendentes". A relação estabelecida entre avós e netos, além do afeto, transmite para a infância uma herança cultural, de maneira simbólica, essencial para a formação da subjetividade da criança, de sua família e de toda a sociedade. (Silva \& Correia, 2014). 
O trabalho realizado por Silva \& Correia (2014) destaca a relevância da literatura como forma de crianças e adultos adentrarem no mundo artístico e cultural:

A cultura, assim como a concebemos, é primordial na constituição do indivíduo, de sorte que a literatura é um meio importante de difusão dos valores culturais que regem uma sociedade elou uma civilização, atingindo facilmente com seu caráter maravilhoso a infância, constituindose um componente de formação de consciência cultural que permitirá um desenvolvimento integral. (Silva \& Correia, 2014, p. 126).

O papel do contador de histórias é assumido na maioria das vezes pelos avós, quando há na constituição familiar a presença destes que muito contribuem para a formação do caráter dos jovens e composição da família. A literatura infantil é uma ferramenta que auxilia na reflexão sobre a construção do universo simbólico e a apropriação das heranças transmitidas e ressignificadas por avós e seus netos. (Silva \& Correia, 2014).

A literatura, juntamente com o meio social são instrumentos que atuam como agentes de transformações. Ao se contar ou ler uma história para alguém, é possível que cada indivíduo vivencie o conteúdo de uma maneira singular e o elabore de acordo com sua realidade. Essa elaboração acarreta um posicionamento crítico de sua realidade, de sua própria história. (Silva \& Correia, 2014).

Ao analisar a presença da literatura infantil nas salas de aula, é possível notar que a maioria das instituições não enfatizam, ou não incluem os contos de fadas infantis no conteúdo a ser ministrado em sala de aula, pois a prioridade das escolas é o conteúdo cartesiano dos livros didáticos. (Oliveira, 2006).

De acordo com a pesquisa de Oliveira (2006) a metodologia escolar que se tem hoje é explicada a partir do argumento de que a escola deve ensinar conteúdos que estão presentes na realidade do aluno, cenário em que os contos de fadas são considerados fuga desta realidade, pois distanciam-se da lição ministrada da realidade cotidiana, e com isso prejudica-se o currículo escolar.

A inclusão dos contos nas salas de aula é de demasiada relevância cultural e simbólica, posto que famílias onde não há os avós, que como dito anteriormente são os que assumem o papel de contador de histórias na maioria das vezes, deixam a criança empobrecida do conteúdo literário infantil. Sendo assim, a escola é um dos espaços onde a literatura infantil poderia ser explorada, de modo a enriquecer a 
criatividade, o intelecto e as fantasias dos alunos.

Em seus estudos, Oliveira (2006) aponta que os contos quando apresentados aos jovens durante sua infância, além de promover o desenvolvimento da criança, também apresentam benefícios a longo prazo. Os contos são recursos que movimentam o raciocínio infantil, posteriormente tornando o adulto fortalecido em suas defesas psíquicas e resultando no processo de elaboração e solução de demandas da vida real, o que contribui também para o enfretamento dos obstáculos da vida, das inseguranças e limitações presentes no cotidiano.

$\mathrm{Na}$ revisão bibliográfica realizada por Oliveira (2006) na obra A psicanálise dos contos de fada de Bettelheim (1980) verificamos o que pode acontecer a um jovem que se desenvolveu sem espaço para expressar e enriquecer sua imaginação e seu intelecto:

As crianças levadas a agir, prematuramente, de forma adulta tendem a suprir a falta das experiências mágicas através da fuga da realidade e que quando adultos compensam essa lacuna com drogas $e$ vícios, pois foram impedidas de desenvolver o senso crítico de que os obstáculos da vida real podem ser encarados e resolvidos por modos realistas, sem necessidade de refugiarse em projeções infantis tendo que regredir em seu contexto histórico. Assim, os contos de fadas ao fornecer respostas sugestivas às ansiedades infantis e visões de mundo diferenciadas possibilitam-lhe dados que irão subsidiar sua vida adulta. (Oliveira, 2006, p. 04).

O uso do elemento fantástico presente nos contos contribui para a melhor assimilação infantil e possibilita que a imaginação do ouvinte dê significados particulares ao conteúdo que está sendo a ele apresentado. Desse modo, cada ouvinte interpreta o conto de uma maneira particular, pois traz para a sua realidade os acontecimentos que tiveram mais relevância do seu ponto de vista.

A diversidade de emoções e acontecimentos bons e ruins torna mais realista as histórias vividas pelos protagonistas, pois a realidade daqueles que a escutam e leem também é repleta de situações e sentimentos agradáveis e também angustiantes.

Costa (2015) realizou uma pesquisa onde analisa as crianças protagonistas dos contos de fadas dos irmãos Grimm, e constatou que estas, (como Chapeuzinho Vermelho, O Pequeno Polegar, João e Maria e Branca de Neve), são como as crianças que ouvem as histórias.A escolha 
desses contos em foi realizada embasada na expressão dos desejos e ansiedades infantis representadas através das ações e sentimentos dos protagonistas.

Freud, no âmbito da segunda tópica, em o Ego e o Id, (1923/1976) aponta que a psique humana é constituída dinamicamente de três estruturas: o Id (regido pelo princípio do prazer), o ego (regido pelo princípio da realidade) e o superego (princípio moral). $\mathrm{O}$ sujeito quando nasce tem o Id como estrutura vigente, e as demais estruturas serão posteriormente desenvolvidas através da relação do indivíduo com o meio externo. Por conseguinte, as crianças buscam sempre a satisfação de seus desejos, e vivem em função do prazer. Essa busca por aquilo que gera prazer e satisfação está presente na linguagem dos contos de fadas,

\section{Considerações Finais}

Através deste estudo, pudemos constatar (com destaque para a relevância que o costume de contar histórias às crianças possui), a relação transgeracional estabelecida durante as narrativas de histórias e os benefícios que os contos trazem ao psiquismo infantil. Com efeito, a narrativa de histórias enriquece os recursos psíquicos de fantasia e criatividade, o que contribui para a resolução de conflitos, que se tornam posteriormente ferramentas aproximando ainda mais o ouvinte com o protagonista do conto. (Costa, 2015).

A diferença de tempo entre a época das histórias que são contadas e a atual, e também as mudanças sociais no decorrer do tempo, não afetaram os comportamentos, fantasias e desejos infantis. Sendo assim, de acordo com Costa (2015) as crianças dos contos de fada e as crianças que compõem a sociedade, vivenciam as mesmas situações como, desamparo, luto, sofrimentos advindos de diferentes circunstâncias. Como nos contos de fadas, as crianças têm sentimentos de amor e ódio, obedecem e desobedecem seus responsáveis, podem ser aventureiras ou medrosas. Como podemos perceber, o comportamento infantil da contemporaneidade e o de outras épocas passadas nos revelam que o modo como os contos foram elaborados é semelhante.

capazes de tornar o adulto um ser humano mais fortalecido diante das adversidades da vida.

O processo de elaboração do luto quando acompanhado de narrativas torna-se menos penoso ao ego, pois o conto metaforiza toda a dor do sujeito de maneira que a criança seja capaz de identificar-se com a perda que os personagens das histórias sofrem. A identificação com o protagonista proporciona ao ouvinte 
vislumbrar uma solução para suas próprias perdas.

Para a criança, a morte pode ser encarada como uma punição por seu comportamento, ou como algo reversível, pois dependendo da idade, o psiquismo infantil se nutre de fantasias as quais tem como objetivo explicar o que é a morte. Quando a morte de um objeto de amor é noticiada a uma criança, se esta for amparada e tiver suas dúvidas sanadas de forma que esclareça o que é a morte, ela terá melhores condições de enfrentar o processo de luto e superá-lo.

\section{Referências}

American Psychiatric Association e outros. Manual diagnóstico e Estatístico de Transtornos Mentais-: DSM-5. Artmed Editora, 2014.

Anton, M. C. \& Favero E. (2011). Morte repentina de genitores e luto infantil: uma revisão da literatura em periódicos científicos brasileiros. Interação Psicológica, 15(1), 101-110. Disponível em : < http://cdpsi.com.br/blog/wp-content/uploads/2015/08/MORTEREPENTINA-DOS-GENITORES.pdf $>$ Acesso em: 29 set. 2016.

Bettelheim, B. (1980). A psicanálise dos contos de fadas. (Trad. Arlene Caetano) 11ed. São Paulo: Paz e Terra, 1980.

Cavalcanti, A. K. S., Samozuk, M. L., \& Bonfim, T. E. (2013). O conceito psicanalítico do luto: uma perspectiva a partir de Freud e Klein. Psicólogo inFormação, 17(17). Recuperado em 06 de junho, 2016. Disponível em https://www.metodista.br/revistas/revistasims/index.php/PINFOR/article/view/4552 : Acesso: 16/05/2016.

Costa, A. B. F. D. (2015). As crianças protagonistas dos contos de fadas dos Irmãos Grimm. Disponível em: https://repositorio.unesp.br/bitstream/handle/11449/136530/000860388.pdf?sequence $=1$ Acesso em : 17/10/2016

Freud, S. (1917/1974). Luto e melancolia. In S. Freud, Edição standard brasileira das obras psicológicas completas de Sigmund Freud (Vol. 14, pp. 275-291). Rio de Janeiro: Imago. (Trabalho original publicado em 1917). Disponível em: < https://carlosbarros666.files.wordpress.com/2010/10/lutoemelancolia1.pdf > Acesso em: 07 jun. 2016.

Freud, S. (1921/1976). O Ego e o Id. In. Sigmund. Freud, Edição standard brasileira das obras psicológicas completas de Sigmund Freud. Tradução de. Salomão J. v. 19. Rio Janeiro: Imago. 1976.

Gutfreind, C. (2003). Terapeuta e o Lobo. São Paulo: Casa do Psicólogo.

Klein, M. (1940/1996). O luto e suas relações com os estados maníaco-depressivos (1940). In:. Amor, culpa e reparação e outros trabalhos (1921-1945). Obras Completas de Melanie 
Klein. Vol. I, Rio de Janeiro: Imago, 1996. Disponível em: https://www.passeidireto.com/arquivo/10959872/6---klein-1940-o-luto-e-suas-relacoes-comos-estados-maniacos-depressi-vos/10 . Acesso em: 07 jun. 2016.

Oliveira, M. E. N. de. (2006). A contribuição dos contos de fadas na formação humana. Educação Pedagógica, Ano 4. n. 12, v. 2: 17- 21, out-dez/2006. Disponível em:< http://www.ie.ufmt.br/semiedu2009/gts/gt17/Poster/MARIA\%20ELIZABETE\%20NASC IMENTO\%20DE\%20OLIVEIRA.pdf>. Acesso em: 16/05/2016.

Organização Mundial da Saúde (1994). CID-10: Classificação Estatística Internacional de Doenças com disquete Vol. 1. Edusp.

Roudinesco, E. (1998). Dicionário de psicanálise. Zahar. Disponível em: https://books.google.com.br/books?hl=pt-

BR\&lr=\&id=kH2j6hJPKm4C\&oi=fnd\&pg=PA1\&dq=roudinesco\&ots=LhHxej5IKd\&sig $=\mathrm{yu} 8 \mathrm{cG} 2 \mathrm{er}$-Ut_gjvpWAUJPXMZX4\#v=onepage $\& \mathrm{q}=$ roudinesco $\& \mathrm{f}=$ false $\quad$ Acesso: $25 / 11 / 2016$

Silva, C. C.F.M. \& Correa, M.R.. (2014). Trocas simbólicas entre gerações: avós, netos e a literatura infantil. Pensando familias, 18(1), 124-137. Recuperado em 17 de junho de 2017, de $\quad$ http://pepsic.bvsalud.org/scielo.php?script=sci_arttext\&pid=S1679494X2014000100011\&lng=pt\&tlng=pt : Acesso: 15/10/2016

Zatti, C., \& Kern, C. (2014). A importância dos contos de fadas como instrumento de trabalho para a psicoterapia infantil. Diaphora, 14(2), 6-17. Recuperado de http://www.sprgs.org.br/diaphora/ojs/index.php/diaphora/article/view/60 : Acesso: 16/05/2016.

Notas de roda pé

${ }^{1}$ Esse termo designou, num primeiro momento, a sede da consciência. O eu/ego foi então delimitado num sistema chamado primeira tópica*, que abrangia o consciente*, o pré-consciente* e o inconsciente*. A partir de 1920, o termo mudou de estatuto, sendo conceituado por Freud como uma instância psíquica, no contexto de uma segunda tópica que abrangia outras duas instâncias: o supereu* e o isso*. O eu/ego tornou-se então, em grande parte, inconsciente. Roudinesco, E. e Plon, M. 1998. p. 210.

\section{A autora:}

Jennifer Guimarães de Moura atualmente desempenha o cargo de escrivã comissionada e psicóloga na Delegacia Especializada no Atendimento à Mulher - DEAM - Rio Verde/GO. Graduada em Psicologia pela Universidade Federal de Goiás - UFG - Regional Jataí. Pós-graduada em Psicologia Jurídica pelo Instituto Paulista de Estudos Bioéticos e Jurídicos - IPEBJ - Ribeirão Preto - SP. E-mail: jennifermoura6@ gmail.com

Maria de Fátima Pessoa Assis - possui graduação em Psicologia pela Universidade Federal de Minas Gerais (1989), Mestrado em Educação pela Universidade Federal de Minas Gerais (1999) e Doutorado em Educação escolar pela Universidade Estadual Paulista, UNESP/Araraquara (2012). Atualmente é professora AdjuntoII, da Universidade Federal de Goiás, onde atua no curso de psicologia do Campus Jataí.

Recebido em: 16/06/2017

Aprovado em: 04/12/2017 